\title{
Review Article \\ The Choice of the Iodinated Radiographic Contrast Media to Prevent Contrast-Induced Nephropathy
}

\author{
Michele Andreucci, ${ }^{1}$ Teresa Faga, ${ }^{1}$ Antonio Pisani, ${ }^{2}$ Massimo Sabbatini, ${ }^{2}$ \\ Domenico Russo, ${ }^{2}$ and Ashour Michael ${ }^{1}$ \\ ${ }^{1}$ Nephrology Unit, Department of "Health Sciences", "Magna Graecia” University, Campus "Salvatore Venuta", \\ Viale Europa, loc. Germaneto, 88100 Catanzaro, Italy \\ ${ }^{2}$ Nephrology Unit, Department of "Public Health", "Federico II" University, Via Pansini No. 5, 80131 Naples, Italy
}

Correspondence should be addressed to Michele Andreucci; andreucci@unicz.it

Received 11 June 2014; Revised 31 August 2014; Accepted 8 September 2014; Published 15 October 2014

Academic Editor: Jane Black

Copyright ( 2014 Michele Andreucci et al. This is an open access article distributed under the Creative Commons Attribution License, which permits unrestricted use, distribution, and reproduction in any medium, provided the original work is properly cited.

In patients with preexisting renal impairment, particularly those who are diabetic, the iodinated radiographic contrast media may cause contrast-induced nephropathy (CIN) or contrast-induced acute kidney injury (CI-AKI), that is, an acute renal failure (ARF), usually nonoliguric and asymptomatic, occurring 24 to 72 hours after their intravascular injection in the absence of an alternative aetiology. Radiographic contrast media have different osmolalities and viscosities. They have also a different nephrotoxicity. In order to prevent CIN, the least nephrotoxic contrast media should be chosen, at the lowest dosage possible. Other prevention measures should include discontinuation of potentially nephrotoxic drugs, adequate hydration with i.v. infusion of either normal saline or bicarbonate solution, and eventually use of antioxidants, such as $\mathrm{N}$-acetylcysteine, and statins.

\section{Introduction}

Iodinated radiographic contrast media [1] are widely used in clinical practice, for both diagnostic and therapeutic procedures such as radiography, percutaneous cardiac and arterial interventions, and contrast-enhanced computed tomography (CT). The intravascular injection of CM is usually safe in healthy subjects with normal renal function. But in patients with preexisting renal impairment the CM may express their nephrotoxicity. Since the clinical need for diagnostic and therapeutic procedures using CM is increased in particular in patients with cardiovascular diseases whose renal function is frequently impaired [2], the occurrence of renal damage by $\mathrm{CM}$ is quite frequent.

Contrast-induced nephropathy (CIN) is defined as an acute renal failure (ARF) occurring 24 to 72 hours after the intravascular injection of radiographic contrast media in the absence of an alternative aetiology [3]. The KDIGO Group [4] "proposes that the term contrast-induced acute kidney injury (CI-AKI) be used for patients developing AKI secondary to intravascular radiocontrast media exposure" rather than CIN. But CIN is still widely used in the literature. It is also questioned whether to use the term ARF to indicate renal impairment by CM. The KDIGO Group also underlines that "the term "acute kidney injury/impairment" has been proposed to encompass the entire spectrum of the syndrome from minor changes in markers of renal function to requirement for renal replacement therapy (RRT)" [4]. However, most authors keep defining AKI as an "ARF" sometimes "renal insufficiency," even without the need for dialysis. It is usually a nonoliguric, asymptomatic, and transient decline in renal function. The renal function is evaluated by measuring serum creatinine ( $\mathrm{SCr}$ ) which is more accurately calculated by using the estimated glomerular filtration rate (eGFR), that is, the creatinine clearance $(\mathrm{CrCl})$ calculated either by the MDRD (modification of diet in renal disease) formula [5] or by the Cockcroft-Gault formula: (140 - number of years of age $\times \mathrm{kg}$ body weight $/ 72 / \mathrm{SCr}(\mathrm{mg} / \mathrm{dL})$; in females the result is multiplied by 0.85 [6]. In addition to giving a better value of renal function, this avoids the tedious procedure of urine 


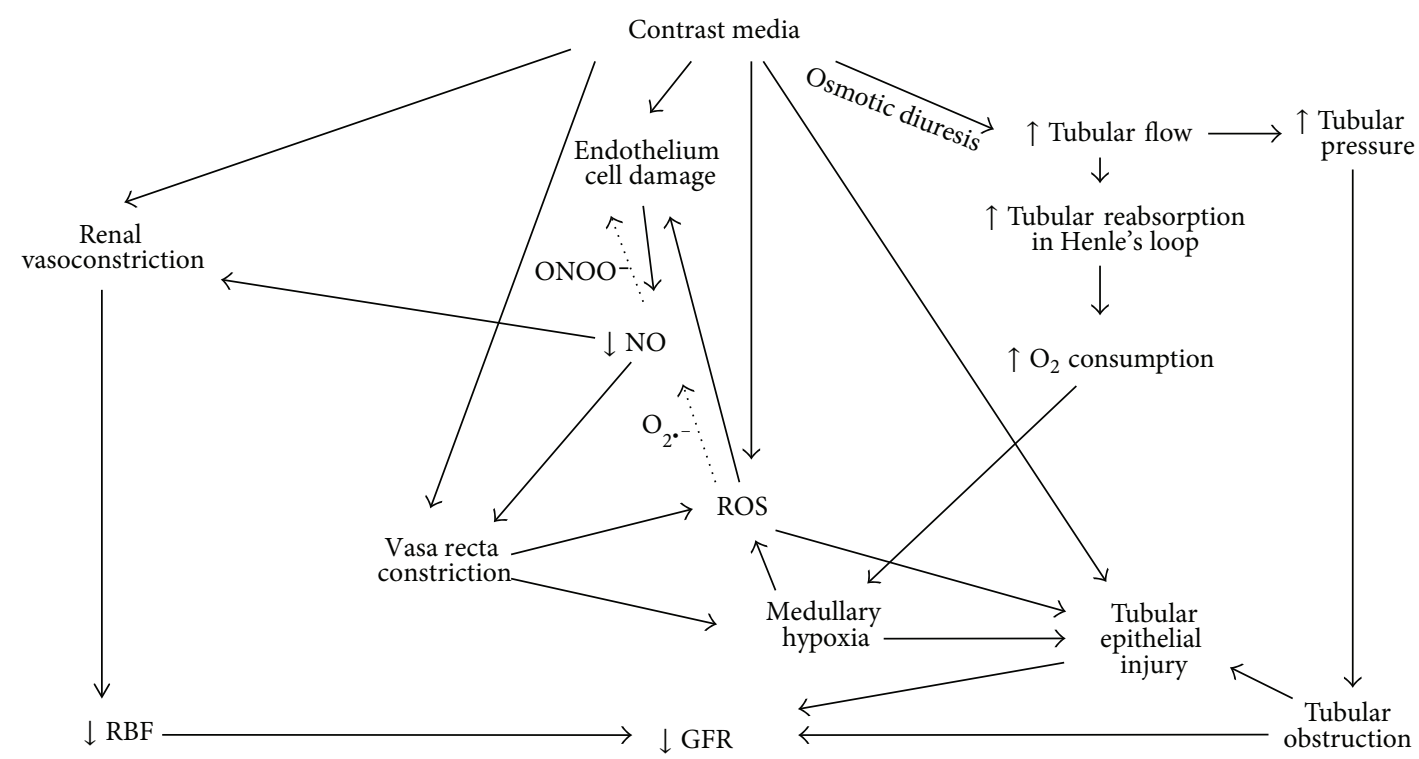

FIGURE 1: The mechanisms by which radiographic contrast media cause a fall of GFR (reproduced and modified from [8], with permission).

collection necessary to measure $\mathrm{CrCl}$. The $\mathrm{CIN}$ is an increase of SCr by $0.5 \mathrm{mg} / \mathrm{dL}$ (or more) or by a $25 \%$ (or more) increase in SCr from baseline or a $\geq 25 \%$ decrease in eGFR [4]. The peak value of SCr and the lowest value of eGFR are observed on the third to fifth day; eGFR returns to baseline within 1014 days. In some cases, CIN is a severe ARF with oliguria $(<400 \mathrm{~mL} / 24 \mathrm{hrs})$, requiring dialysis. In these patients the mortality is high [7].

The clinical features and the management of CIN are the same as those for ARF due to other causes [8-10].

\section{Pathogenesis of CIN}

The pathophysiological mechanisms responsible for CIN have not been fully elucidated [11].

After the intravascular injection, iodinated radiographic CM cause hemodynamic changes: immediate renal vasodilatation with an initial increase in renal blood flow (RBF) followed by prolonged vasoconstriction with an increase in intrarenal vascular resistance and a reduction in total RBF [12].

The extrarenal vessels show transient vasoconstriction followed by a stable decrease in vascular peripheral resistance $[13,14]$ (Figure 1).

The fall in total RBF will cause a decrease in the glomerular filtration rate (GFR). But the renal vasoconstriction causes particularly severe consequences in the renal medulla because of the normally poor oxygen delivery to the outer renal medulla (due to its distance from the descending vasa recta) associated with the high local $\mathrm{O}_{2}$ consumption due to the important tubular reabsorption in S3 segments of proximal renal tubules of the outer medulla and in the medullary thick ascending limbs of Henle's loop. Thus, the haemodynamic changes induced by CM will make medullary hypoxia quite severe (Figure 1).
After CM administration in patients with chronic renal failure, Russo et al. [15] have shown (1) an immediate GFR decline proportional to the osmolality of CM and secondary to the renal hypoperfusion that is not caused by hypovolemia and (2) an early tubular dysfunction at the level of the proximal nephron.

Furthermore, radiographic CM induce an osmotic diuresis and consequently an increase in tubular reabsorption in Henle's loop; the resulting increase of energy need and the high $\mathrm{O}_{2}$ consumption of the ascending limb will make the medullary hypoxia worse $[8,16]$ (Figure 1 ). The osmotic diuresis will increase the intratubular pressure and tubular obstruction thereby contributing to the fall in GFR.

Medullary hypoxia leads to the formation of reactive oxygen species (ROS) $[17,18]$ that may exert direct tubular and vascular endothelial injury and might further intensify renal parenchymal hypoxia by virtue of endothelial dysfunction and dysregulation of tubular transport [19, 20] (Figure 1).

The decrease in nitric oxide (NO) is believed to be due to its reaction with ROS, in particular with superoxide anions $\left(\mathrm{O}_{2}{ }^{\cdot-}\right)[21,22]$. This reaction may lead to the formation of the more powerful oxidant peroxynitrite anion $\left(\mathrm{ONOO}^{-}\right)$ [23] that may be more detrimental to the endothelial cells. Hence the reaction of the ROS with NO not only causes a reduction in the levels of the vasodilator $\mathrm{NO}$, but also leads to the formation of a potent oxidant that exacerbates cell injury.

Pisani et al. [24] have recently demonstrated that a recombinant manganese superoxide dismutase administered in vivo to rats undergoing diatrizoate treatment was able to reduce renal oxidative stress, thereby preventing the reduction of GFR and the renal histologic damage that follows contrast media administration.

Iodinated radiographic contrast media also exert a direct cytotoxic effect on both endothelial and tubular cells that has been suggested to be due, at least in part, to the free iodine present in solutions of CM [21] and leads to apoptosis and 
TABLE 1: Iodinated contrast media used in clinical practice.

\begin{tabular}{|c|c|c|c|c|c|}
\hline Name & Type & $\begin{array}{c}\text { Iodine content } \\
\mathrm{mg} / \mathrm{mL}\end{array}$ & $\begin{array}{c}\text { OSM } \\
\mathrm{mOsm} / \mathrm{kg}\end{array}$ & $\begin{array}{c}\text { Osmolality } \\
\text { type }\end{array}$ & $\begin{array}{c}\text { Viscosity } \\
\text { Cps at } 37^{\circ} \mathrm{C} \\
\end{array}$ \\
\hline \multicolumn{6}{|l|}{ Ionic } \\
\hline Diatrizoate (Hypaque 50, Renografin) & Monomer & 300 & 1,550 & HOCM & 10.5 \\
\hline Metrizoate (Isopaque 370) & Monomer & 370 & 2,100 & HOCM & 3.4 \\
\hline Iothalamate (Conray) & Monomer & 325 & 1843 & HOCM & 4.0 \\
\hline Ioxaglate (Hexabrix) & Dimer & 320 & 580 & LOCM & 7.5 \\
\hline \multicolumn{6}{|l|}{ Nonionic } \\
\hline Iopamidol (Isovue-370) & Monomer & 370 & 796 & LOCM & 9.4 \\
\hline Iohexol (Omnipaque 350) & Monomer & 350 & 884 & LOCM & 10.4 \\
\hline Iodixanol (Visipaque 320) & Dimer & 320 & 290 & IOCM & 11.8 \\
\hline Iotrolan (Isovist) & Dimer & 300 & 320 & IOCM & 8.1 \\
\hline Ioxaglate (Hexabrix) & Dimer & 320 & 600 & LOCM & 7.5 \\
\hline Ioxilan (Oxilan 350) & Monomer & 350 & 695 & LOCM & 8.1 \\
\hline Iopromide (Ultravist 370) & Monomer & 370 & 774 & LOCM & 10.0 \\
\hline Ioversol (Optiray 300) & Monomer & 300 & 651 & LOCM & 5.5 \\
\hline Iomeprol (Iomeron 350) & Monomer & 350 & 618 & LOCM & 7.5 \\
\hline
\end{tabular}

Ionic and nonionic contrast media may be monomeric or dimeric; 3 iodine atoms are delivered with each benzene ring of a contrast medium: if a contrast molecule contains only 1 benzene ring, it is called a monomer; if it contains 2 benzene rings, it is called a dimer. In a solution, ionic contrast media break up into their anion and cation components, thereby increasing osmolality, while nonionic contrast media do not break up in solution. Nonionic dimers are the ideal contrast media as they deliver the most iodine with the least effect on osmolality.

The osmolality of contrast media is compared with the osmolality of plasma. HOCM = high osmotic contrast media have the highest osmolality, that is, 5-8 times the osmolality of plasma. LOCM = low osmotic contrast media have an osmolality still higher than plasma, that is, 2-3 times the osmolality of plasma. IOCM = isoosmotic contrast media have the same osmolality as plasma. Cps: viscosity in centipoise.

Most data of viscosity are from [118].

(Reproduced and modified from [8], with permission)

cell death. The decrease in NO in the vasa recta is due not only to increased ROS production, but also to its reduced release by damaged endothelial cells (including those undergoing apoptosis) $[21,25,26]$.

\section{The Differences between Iodinated Radiographic CM}

Radiographic CM have different osmolalities (see Table 1). The ionic high-osmolar contrast media (HOCM, e.g., diatrizoate) have an osmolality of 1500 to $1800 \mathrm{mOsm} / \mathrm{kg}$, that is, 58 times the osmolality of plasma. Nonionic low-osmolar contrast media (LOCM, e.g., iohexol) have an osmolality of 600 to $850 \mathrm{mOsm} / \mathrm{kg}$, that is, $2-3$ times the osmolality of plasma. Nonionic isoosmolar contrast media (IOCM, e.g., iodixanol) have an osmolality of approximately $290 \mathrm{mOsm} / \mathrm{kg}$, that is, the same osmolality as plasma $[16,27]$. The LOCM are less nephrotoxic than HOCM. The frequency of adverse reactions to $\mathrm{CM}$ ranges from $5 \%$ to $12 \%$ for $\mathrm{HOCM}$ and from $1 \%$ to $3 \%$ for LOCM. It has been observed that the use of LOCM rather than HOCM is beneficial in the prevention of CIN in patients with preexisting chronic renal failure [2831]. Thus, the HOCM are rarely used. The IOCM iodixanol seems less nephrotoxic than the LOCM iohexol, at least in patients with intra-arterial administration of the drug and renal insufficiency $[32,33]$.

\section{Factors Increasing Nephrotoxicity of CM}

As already mentioned, preexisting impairment of renal function, irrespective of cause, greatly favors the occurrence of
CIN. The higher the baseline creatinine value or, better, the lower the eGFR, the greater the risk of CIN [8].

Diabetes mellitus is another predisposing factor for the development of CIN, particularly when associated with renal insufficiency [34]. At any given degree of baseline GFR, diabetes doubles the risk of developing CIN compared with non-diabetic patients. The incidence of CIN in diabetic patients varies from 5.7 to $29.4 \%$ [35]. Coupling chronic kidney disease and diabetes dramatically increases the risk for CIN compared with that observed for chronic kidney disease alone [36].

The concomitant use of nephrotoxic drugs, such as aminoglycosides, cyclosporin A, amphotericin, cisplatin, and nonsteroidal anti-inflammatory drugs, is undoubtedly another factor favoring the onset of CIN [8].

Most authors believe that patients with chronic renal disease under treatment with angiotensin-converting enzyme inhibitors (ACEIs) or angiotensin II receptor blockers (ARBs) are at higher risk for developing CIN [37-42] particularly in the elderly [43]. According to KDIGO (kidney disease improving global outcome) guidelines for Acute Kidney Injury Work Group, there is insufficient evidence to recommend discontinuation of these medications prior to contrast administration [4].

Dehydration and/or volume contraction and reduction of "effective" circulating blood volume are major individual risk factors for CIN [8].

Use of large doses of contrast media and their multiple injections within $72 \mathrm{hrs}$ increases the risk of CIN [44-49].

Advance age ( $>65$ years), anemia, congestive heart failure, sepsis, and renal transplant all predispose to CIN [8]. 


\section{The Effect of the Route of Administration on Nephrotoxicity of CM}

CIN occurs more frequently after intra-arterial than after i.v. contrast medium administration $[32,50]$, probably because of the higher acute intrarenal concentration, particularly if the arterial injection is suprarenal [51-57]. The closer to the renal arteries the injection of contrast medium occurs, the higher the risk of CIN appears to be [57].

The meta-analysis by Dong et al. [32] obtained from 18 randomized controlled trials including 3,129 patients showed that the IOCM iodixanol significantly decreased the risk of CIN as compared with a pool of LOCM (iopromide, iopamidol, iohexol, ioversol, ioxaglate, and iomeprol) when contrast media were given intra-arterially (11 trials). In contrast, it was not associated with a reduction in CIN compared with the LOCM (iopromide, iopamidol, iomeprol, and iohexol) pooled together following i.v. application (7 trials). Probably the different nephrotoxicity between the intra-arterial and the i.v. administration of contrast media is accounted for by the different reactions to oxidative stress between arteries and veins [32].

\section{Viscosity of $\mathbf{C M}$}

Contrast media share common iodine-related cytotoxic features but differ considerably with regard to osmolality and viscosity (Table 1). According to some authors [58-60], in fact, in addition to their osmolality the viscosity of CM is also very important.

Fluid viscosity is a measure of the fluid's resistance to flow due to friction between neighboring parcels that are moved at different velocities. Radiographic CM are tri-iodinated benzene derivatives. Their radioopacity relies on iodine. Thus, solutions with high iodine concentration (usually with 250$400 \mathrm{mg} \mathrm{I} / \mathrm{mL}$ ) are required. This is obtained by high molar concentrations of benzene derivatives that are responsible for the osmolality and viscosity of the solution. The osmolality of the CM solution increases linearly with the molar concentration, while the viscosity increases exponentially [58].

The low osmolality achieved with the IOCM occurred at the price of considerably increased viscosity at comparable iodine concentration and X-ray attenuation; nonionic dimeric IOCM have about twice the viscosity of nonionic monomeric LOCM [60-62].

The CM are freely filtered by the glomeruli so that their concentration in primary urine equals that of the blood plasma entering the kidney. They are not reabsorbed by tubules. Most of the water and salt filtered by the glomeruli, however, is reabsorbed along the renal tubules, particularly the proximal tubules. Thus, the concentration of $\mathrm{CM}$ increases considerably within the tubular lumen. According to Seeliger et al. [58-60] the high viscosity of CM may contribute to their nephrotoxicity. The increase of CM concentration will cause a progressive increase in tubular fluid osmolality and, due to the exponential concentrationviscosity relationship, an overproportional increase in tubular fluid viscosity $[16,58]$. Since the fluid flow rate through a tube increases with the pressure gradient and decreases with the flow resistance and since the resistance increases proportionally to fluid viscosity, the increased viscosity caused by the contrast medium concentrated within the tubule increases the intratubular pressure [58]. This hypothesis has been validated by the studies of Ueda et al. [63, 64] who measured the intratubular pressure in proximal and distal convoluted renal tubules by micropuncture techniques. These authors, in fact, with micropuncture studies in rats found that the IOCM, iotrolan, increased tubular pressure much more and decreased single nephron GFR much more as compared with the HOCM and LOCM studied. Thus, the high intratubular pressure will have four consequences: (a) it hinders the glomerular filtration, thereby reducing tubular flow rate; (b) the reduction of tubular flow prolongs the contact time of cytotoxic CM with the tubular epithelium, consequently making the injury to the epithelial tubular cells more severe; (c) the high intratubular pressure contributes to medullary hypoperfusion and hypoxia: in presence of a tough renal capsule, in fact, the circular distension of the tubules will lead to compression of medullary vasa recta; (d) the reduced blood flow rate in the latter will increase the contact time of cytotoxic CM with the vascular endothelium contributing to its damage $[16,58]$. In conclusion, the $\mathrm{CM}$ viscosity would contribute to the overall nephrotoxicity of CM.

\section{Cytotoxic Effects of CM In Vitro}

Heinrich et al. [65] compared the cytotoxic effects of dimeric and monomeric iodinated $\mathrm{CM}$ on renal tubular cells in vitro. Cell viability was assessed by using the 3-(4,5dimethyl-2-thiazolyl)-2,5-diphenyl-2H-tetrazolium bromide (MTT) uptake assay. The conversion of MTT, a tetrazolium salt, into formazan depends on the activity of a group of mitochondrial dehydrogenases and, thus, is an indicator of cell metabolic activity [65]. Results of this study indicated that HOCM have a greater potential for cytotoxic effects on proximal renal tubular cells in vitro than LOCM or IOCM do. At equal iodine concentrations (300 $\mathrm{mg} \mathrm{I} / \mathrm{mL})$, the HOCM ioxithalamate showed stronger cytotoxic effects than other contrast media did: MTT conversion for the HOCM ioxithalamate was $4 \%$ versus that for the LOCM ioversol of $32 \%$, that for the LOCM iomeprol-300 of 34\%, that for the IOCM iodixanol of $40 \%$, and that for the IOCM iotrolan of $41 \%$ of undamaged control cells at $75 \mathrm{mg}$ of iodine per milliliter $(P<0.001)$; there was no significant difference between monomeric LOCM and dimeric IOCM $(P>0.05)$. Thus, there is no difference in the cytotoxicity of LOCM iomeprol and IOCM iodixanol at equal iodine concentrations in renal proximal tubular cells in vitro [33].

Michael et al. [66] and Andreucci et al. [67-70] have investigated the signaling pathways in renal tubular cell lines (including primary human renal tubular cells) that may be affected by exposure of renal tubular cells to CM. The incubation of human renal tubular proximal cells with the HOCM sodium diatrizoate, the LOCM iopromide, and the LOCM iomeprol caused a marked dephosphorylation of the kinase Akt on Ser473 within 5 min of incubation. This observation is remarkable given the suggestion that CM give 
rise to ROS [66] and treatment of renal cells with powerful oxidants or subjecting renal cells to conditions that favour ROS formation cause an increase in Akt phosphorylation in renal tubular cells [71-73]. All of these CM also caused a decrease in cell viability [68-70], which was substantially alleviated by transfecting the cells with a constitutively active form of Akt [68]. Further downstream targets of Akt, including the Forkhead family of transcription factors FKHR and FKHRL1, were also dephosphorylated by the three CM at Thr24 and Thr32, respectively. The p70S6 kinase was also dephosphorylated at Thr389 and Ser371 by these CM [68].

The HOCM sodium diatrizoate and the LOCM iomeprol at a concentration of $75 \mathrm{mg} \mathrm{I} / \mathrm{mL}$ for $2 \mathrm{~h}$ have been shown, by the same authors, to cause an increase in phosphorylation of p38 mitogen-activated protein kinase (MAPK) (p38) and cJun $\mathrm{N}$-terminal kinases (JNKs) and NF- $\kappa \mathrm{B}$ (at Ser276), with sodium diatrizoate having a more drastic effect. Although cell viability was reduced significantly by both $\mathrm{CM}$, in cells pretreated with the LOCM iomeprol the cell viability recovered over a $22 \mathrm{~h}$ time period after removal of the CM. However, viability of diatrizoate-treated cells rose at $5 \mathrm{~h}$ but then fell at $22 \mathrm{~h}$ after removal of the RCM. The decrease in cell viability in diatrizoate-treated cells corresponded with an increase in phosphorylation of JNKs, p38, and NF- $\kappa$ B and a decrease in phosphorylation of Akt, signal transducer and activator of transcription (STAT) 3, and forkhead box O3a, as well as poly (ADP-ribose) polymerase (PARP) and caspase-3 cleavage. The recovery in viability of the LOCM iomeproltreated cells corresponded most notably with an increase in STAT3 phosphorylation and induction of Pim-1 kinase. There was also an increase in interleukin-8 release by diatrizoatetreated cells indicating the possibility of proinflammatory effects of this CM [69].

The same group has recently compared the changes of intracellular signaling pathways affected by the LOCM iomeprol and the IOCM iodixanol. Both CM caused a dramatic decrease in phosphorylation of the kinase Akt at Ser473 and Thr308 in human proximal renal tubular cells, with iomeprol having a greater effect and causing a greater decrease in cell viability. Iodixanol caused a greater decrease in the phosphorylation of the extracellular-signal regulated kinases (ERKs) 1 and 2 and mammalian target of rapamycin (mTOR), but both CM caused a similar decrease in the phosphorylation of phospho-p70S6 kinase (at Ser371) [70].

\section{Protection by Adequate Hydration}

Under normal physiological circumstances the entity of tubular reabsorption of water and salt depends on the subject's hydration and volume status. In subjects who are dehydrated and/or hypovolaemic, physiological mechanisms for water and/or volume preservation are activated, that is, the renin-angiotensin system and vasopressin. This leads to increase of tubular reabsorption of water and salt from the tubular fluid, thereby making the urine more concentrated. This tubular fluid overreabsorption during volume depletion (hypovolemia) does occur already in the proximal tubules. Thus, when CM are injected in dehydrated/hypovolaemic patients, the water and salt overreabsorption will further increase the tubular concentration of $\mathrm{CM}$ and, due to the concentration-viscosity relationship, overproportionally increase the tubular fluid and urine viscosity. This is why dehydration (for instance in the elderly due to impaired sensation of thirst [74]) and/or volume contraction (salt depletion following abnormal gastrointestinal, renal or dermal fluid losses associated with insufficient salt intake and reduction of "effective" circulating blood volume [75]) are major individual risk factors for CIN. Thus, it is a very crucial point to recommend prehydration and correction of volume depletion in all patients before undergoing the diagnostic and therapeutic procedures requiring intravascular injection of CM $[7,58]$. The "effective" circulating blood volume may be defined as the relative fullness of the arterial tree as determined by cardiac output, peripheral vascular resistance, and total blood volume [9]. A reduction of "effective" circulating blood volume may be due to congestive heart failure, compromised left ventricle systolic performance, prolonged hypotension, or liver cirrhosis or nephrotic syndrome [16].

\section{The Different Nephrotoxicity of Different CM}

McCullough et al. [76] had performed a meta-analysis of the renal safety of IOCM iodixanol compared with LOCM, including 16 double-blind, randomized, controlled trials with data from 2,727 patients. They found that the use of the IOCM iodixanol was associated with smaller rises in SCr and lower rates of CIN than LOCM, especially in patients with chronic kidney disease and/or diabetes mellitus.

Most of the recent studies and meta-analyses, however, have found no significant difference in the rates of CIN between IOCM and LOCM [8, 32, 33, 50, 77-79].

Thus, the meta-analysis of Heinrich et al. [33] that included 25 randomized controlled trials with data from 2,850 patients compared the nephrotoxicity of IOCM iodixanol (1701 patients) with that of LOCM (iohexol, iopamidol, iopromide, iomeprol, ioversol, and iobitridol) (1569 patients). They found that iodixanol did not significantly reduce the risk of CIN after i.v. administration of the CM (8 trials) as compared with LOCM pooled together. However, in patients with intra-arterial administration (17 trials) and renal insufficiency, they found that the risk of CIN was greater for the LOCM iohexol (494 patients) than for IOCM iodixanol, whereas no significant difference between iodixanol and other LOCM could be found.

Reed et al. [78] conducted another meta-analysis (16 trials including 2,763 subjects) also comparing the nephrotoxicity of the IOCM iodixanol to LOCM. They found no significant difference in the incidence of CIN between the iodixanol group and the LOCM group. They admitted that the relative renal safety of LOCM compared with iodixanol may vary depending on the particular type of LOCM.

The study PREDICT (patients with renal impairment and diabetes undergoing CT) compared the incidence of CIN after administration of either LOCM iopamidol 370 (n. 125) or IOCM iodixanol 320 (n. 123) in patients with diabetes and 
chronic renal insufficiency $\left(\mathrm{eGFR}=20-59 \mathrm{~mL} / \mathrm{min} / 1.73 \mathrm{~m}^{2}\right)$ undergoing CT. CIN (increase in the serum creatinine of $\geq 25 \%$ from the baseline level) occurred in 7 patients $(5.6 \%)$ receiving iopamidol 370 and in 6 patients $(4.9 \%)$ receiving iodixanol $320(P=1.0)$. The authors concluded that there is no difference in the incidence of CIN between iopamidol and iodixanol in patients with diabetes and chronic renal insufficiency [50].

Barrett et al. [80] compared the effects on renal function of equi-iodine i.v. doses ( $40 \mathrm{gI})$ of either LOCM iopamidol 370 (n. 77) or IOCM iodixanol 320 (n. 76) in 153 patients with chronic kidney disease ( $\mathrm{SCr}, \geq 1.5 \mathrm{mg} / \mathrm{dL}$, and/or $\mathrm{CrCl}$, $\geq 60 \mathrm{~mL} / \mathrm{min}$ ) undergoing contrast-enhanced multidetector CT using a multicenter, double-blind, randomized, parallelgroup design. An increase of $\geq 0.5 \mathrm{mg} / \mathrm{dL}$ in $\mathrm{SCr}$ was observed in none of the patients receiving iopamidol-370 and in two of the patients receiving iodixanol-320 $(P=0.2)$. An increase of $\geq 25 \%$ in SCr occurred in three of the patients receiving iopamidol-370 and in three of the patients receiving iodixanol-320 $(P=1.0)$. The authors concluded that the incidence of CIN was similarly low in risk patients after i.v. administration of iopamidol-370 (LOCM) or iodixanol-320 (IOCM).

Solomon et al. [77] have performed the CARE (Cardiac Angiography in Renally Impaired Patients) trial, a randomized double-blind trial of CIN in patients with chronic kidney disease, enrolling 414 patients with an eGFR of 20 to $59 \mathrm{~mL} / \mathrm{min} / 1.73 \mathrm{~m}^{2}$ who underwent cardiac catheterization by using either LOCM iopamidol or IOCM iodixanol. SCr increase $\geq 0.5 \mathrm{mg} / \mathrm{dL}$ occurred in $4.4 \%$ (9 of 204 patients) after iopamidol and $6.7 \%$ (14 of 210 patients) after iodixanol $(P=0.39)$, whereas $S C r$ increase $\geq 25 \%$ was $9.8 \%$ and $12.4 \%$, respectively $(P=0.44)$. Thus, the incidence of CIN was not different between the two study groups. In patients with diabetes $(n=170)$, there was also no statistically significant difference in the incidence of CIN between iopamidol and iodixanol (10.3\% versus $15.2 \%$, resp.; $P=0.37)$. The authors concluded that the incidence of CIN is not statistically different after the intra-arterial administration of iopamidol or iodixanol to high-risk patients, with or without diabetes mellitus.

\section{The Choice of the $\mathrm{CM}$}

As described above, no significant difference in nephrotoxicity has been found between the IOCM iodixanol and all the LOCM, probably with the only exception being iohexol $[81,82]$. Once it has been decided which CM is to be used, it is very important to take into consideration the dosage of the $\mathrm{CM}$, to limit its nephrotoxicity. The lowest dosage possible of the radiographic contrast agent should be used [16].

High doses of contrast agents are required in percutaneous coronary interventions (PCI). Some formulas have been suggested to calculate the dosage that is least dangerous for renal function [8].

(1) Cigarroa's formula is $5 \mathrm{~mL}$ of contrast per $\mathrm{kg}$ b.w./SCr (mg/dL) with maximum acceptable dose of $300 \mathrm{~mL}$ for diagnostic coronary arteriography [83].
(2) Laskey's formula is volume of contrast to eGFR ratio with a cutoff point of the ratio at 3.7 for PCI. It has been demonstrated that a ratio $>3.7$ is associated with a decrease in $\mathrm{CrCl}$ [84]. More recently Gurm et al. [85] have suggested a cutoff point at 2.0: below a ratio of 2.0 CIN would be a rare complication of PCI, but it would increase dramatically at a ratio of 3.0.

(3) A new formula seems to be superior and takes into consideration the ratio of grams of iodine to the eGFR; it has been suggested that a ratio of 1.42, or even better a ratio of 1.0 , would prevent CIN [86].

Obviously, all other prevention measures should be made in order to prevent the onset of CIN as follows [8, 87]. (A) Monitoring of the eGFR before and once daily for 5 days after the radiographic procedure and consider that patients with coronary artery disease may have initial and silent renal dysfunction [2]. (B) Discontinuation of potentially nephrotoxic drugs (aminoglycosides, vancomycin, amphotericin B, metformin, and nonsteroidal anti-inflammatory drugs). (C) Adequate hydration, in the opinion of some authors, by giving $500 \mathrm{~mL}$ of water or soft drinks orally before and $2,500 \mathrm{~mL}$ for 24 hours after contrast administration in order to secure urine output of at least $1 \mathrm{~mL} / \mathrm{min}$ in a nondehydrated patient [88]). It is undoubtedly better to give i.v. infusion of saline or a bicarbonate solution since the water alone will dilute the tubular fluid only in the collecting ducts, thereby giving no protection at all. Thus, Trivedi et al. [89] randomized 53 patients on the day before scheduled elective cardiac catheterization to group 1 (n. 27) that received normal saline for $24 \mathrm{~h}$ (at a rate of $1 \mathrm{~mL} / \mathrm{kg}$ per $\mathrm{h}$ ) beginning $12 \mathrm{~h}$ before scheduled catheterization and group 2 (n. 26) that was allowed unrestricted oral fluids; an increase in SCr by at least $0.5 \mathrm{mg} / \mathrm{dL}$ within $48 \mathrm{~h}$ of contrast exposure was considered to represent clinically significant ARF; the incidence of CIN was significantly lower in group 1 (one out of 27) as compared to group 2 (nine out of 26 ; $P=0.005)$ demonstrating that oral supplement of water has no protective effect as normal saline does. Thus, an i.v. infusion of $0.9 \%$ saline at a rate of $1 \mathrm{~mL} / \mathrm{kg} \mathrm{b}$.w. per hour, beginning 6-12 hours before the procedure and continuing for up to $12-24$ hours after, is suggested, if urine output is appropriate and cardiovascular condition allows it $[48,90]$. Some authors suggest using sodium bicarbonate hydration that has been shown to be superior to sodium chloride in many clinical studies and meta-analysis [91-101]. For coronary angiography or intervention $154 \mathrm{mEq} / \mathrm{L}$ infusion of sodium bicarbonate as a bolus of $3 \mathrm{~mL} / \mathrm{kg} \mathrm{b}$.w./hour for 1 hour before the administration of IRCA, followed by $1 \mathrm{~mL} / \mathrm{kg} /$ hour for 6 hours during and after the procedure, has been used [102]. The alkalinization of tubular fluid by bicarbonate would reduce the production and increase the neutralization of oxygen-free radicals, thereby protecting the kidney from injury by CM. The adequate hydration is undoubtedly the most important preventive measure against CI-AKI. (D) Use of antioxidants, such as N-acetylcysteine in high-risk patients (oral dose of $600 \mathrm{mg}$ twice daily the day before and the day of procedure [48] or an i.v. dose of $150 \mathrm{mg} / \mathrm{kg}$ over half an hour before the procedure or $50 \mathrm{mg} / \mathrm{kg}$ 
administered over 4 hours [103]). (E) Use of statins, which have been demonstrated to be protective also under other circumstances of kidney injury [104-109], for example, shortterm pretreatment with atorvastatin: $80 \mathrm{mg} 12$ hours before intervention with another $40 \mathrm{mg}$ preprocedure, followed by long-term treatment of $40 \mathrm{mg} /$ day [110]. More recently, only in patients with low or medium risk, Quintavalle et al. have shown that a single high loading dose of atorvastatin $(80 \mathrm{mg})$ administered within 24 hours before the CM exposure is effective for the reduction of the rate of CIN [111]. (F) Use of furosemide to reduce salt reabsorption in the thick ascending limb of Henle's loops, thereby reducing oxygen consumption and medullary hypoxia; but several studies have demonstrated no protection against CIN of this diuretic or even deleterious effects mainly related to the salt depletion caused by furosemide [112-114]. To overcome the problem of hypovolemia caused by furosemide, a perfect combination of hydration plus furosemide has been suggested: this is obtained by delivering i.v. fluid in an amount exactly matched to the volume of urine produced by the patient under the effect of furosemide; this procedure was accomplished by a special device, called "RenalGuard," with excellent results $[101,115]$. (G) Use of hemodialysis or hemofiltration to remove $\mathrm{CM}$ immediately after the radiographic procedure; but so far this measure has not diminished the rate of CIN $[116,117]$.

\section{Abbreviations}

CM: Contrast media

AKI: Acute kidney injury

ARF: Acute renal failure

eGFR: Estimated glomerular filtration rate

GFR: Glomerular filtration rate

CIN: Contrast-induced nephropathy

SCr: $\quad$ Serum creatinine

CrCl: Creatinine clearance

RBF: $\quad$ Renal blood flow

CT: $\quad$ Computed tomography

MDRD: Modification of diet in renal disease

NO: $\quad$ Nitric oxide

ROS: $\quad$ Reactive oxygen species

LOCM: Low-osmolar contrast media

HOCM: High-osmolar contrast media

IOCM: Isoosmolar contrast media

MTT: 3-(4,5-Dimethyl-2-thiazolyl)-2,5diphenyl-2H-tetrazolium bromide

PCI: Percutaneous coronary interventions.

\section{Conflict of Interests}

The authors declare that there is no conflict of interests regarding the publication of this paper.

\section{Acknowledgment}

Dr. Ashour Michael is currently recipient of an "Assegno di Ricerca" (Research check) at the "Magna Graecia" University, Catanzaro, Italy.

\section{References}

[1] B. J. Barrett, P. S. Parfrey, H. M. Vavasour et al., "Contrast nephropathy in patients with impaired renal function: high versus low osmolar media," Kidney International, vol. 41, no. 5, pp. 1274-1279, 1992.

[2] G. Fuiano, D. Mancuso, C. Indolfi et al., "Early detection of progressive renal dysfunction in patients with coronary artery disease," Kidney International, vol. 68, no. 6, pp. 2773-2780, 2005.

[3] M. Andreucci, R. Solomon, and A. Tasanarong, "Side effects of radiographic contrast media: pathogenesis, risk factors, and prevention," BioMed Research International, vol. 2014, Article ID 741018, 20 pages, 2014.

[4] Group KDIGOKAKIW, "KDIGO clinical practice guideline for acute kidney injury," Kidney International, vol. 2, supplement, pp. 1-138, 2012.

[5] A. S. Levey, J. P. Bosch, J. B. Lewis, T. Greene, N. Rogers, and D. Roth, "A more accurate method to estimate glomerular filtration rate from serum creatinine: a new prediction equation," Annals of Internal Medicine, vol. 130, no. 6, pp. 461-470, 1999.

[6] D. W. Cockcroft and M. H. Gault, "Prediction of creatinine clearance from serum creatinine," Nephron, vol. 16, no. 1, pp. 3141, 1976.

[7] M. Andreucci, T. Faga, M. Sabbatini, A. Pisani, D. Russo, and A. Michael, "How to prevent contrast-induced nephropathy in clinical practice," Journal of Clinical Nephrology and Research, vol. 1, no. 1, p. 1002, 2014.

[8] M. Andreucci, R. Solomon, and A. Tasanarong, "Side effects of radiographic contrast media: pathogenesis, risk factors, and prevention," BioMed Research International, vol. 2014, Article ID 741018, 20 pages, 2014.

[9] V. E. Andreucci, G. Fuiano, D. Russo, and M. Andreucci, "Vasomotor nephropathy in the elderly," Nephrology Dialysis Transplantation, vol. 13, supplement 7, pp. 17-24, 1998.

[10] V. E. Andreucci, G. Fuiano, P. Stanziale, and M. Andreucci, "Role of renal biopsy in the diagnosis and prognosis of acute renal failure," Kidney International, Supplement, vol. 53, no. 66, pp. S91-S95, 1998.

[11] M. Andreucci, T. Faga, A. Pisani, M. Sabbatini, and A. Michael, "Pathogenesis of acute renal failure induced by iodinated radiographic contrast media," Austin Journal of Nephrology and Hypertension, vol. 1, no. 1, pp. 1-6, 2014.

[12] A. Caiazza, L. Russo, M. Sabbatini, and D. Russo, "Hemodynamic and tubular changes induced by contrast media," BioMed Research International, vol. 2014, Article ID 578974, 7 pages, 2014.

[13] S. W. Murphy, B. J. Barrett, and P. S. Parfrey, "Contrast nephropathy," Journal of the American Society of Nephrology, vol. 11, no. 1, pp. 177-182, 2000.

[14] S. Detrenis, M. Meschi, S. Musini, and G. Savazzi, "Lights and shadows on the pathogenesis of contrast-induced nephropathy: state of the art," Nephrology Dialysis Transplantation, vol. 20, no. 8, pp. 1542-1550, 2005.

[15] D. Russo, R. Minutolo, B. Cianciaruso, B. Memoli, G. Conte, and L. de Nicola, "Early effects of contrast media on renal hemodynamics and tubular function in chronic renal failure," Journal of the American Society of Nephrology, vol. 6, no. 5, pp. 1451-1458, 1995. 
[16] M. Andreucci, T. Faga, A. Pisani, M. Sabbatini, and A. Michael, "Acute kidney injury by radiographic contrast media: pathogenesis and prevention," BioMed Research International, vol. 2014, Article ID 362725, 21 pages, 2014.

[17] A. J. Giaccia, M. C. Simon, and R. Johnson, "The biology of hypoxia: the role of oxygen sensing in development, normal function, and disease," Genes and Development, vol. 18, no. 18, pp. 2183-2194, 2004.

[18] M. Sabbatini, M. Santillo, A. Pisani et al., "Inhibition of Ras/ERK1/2 signaling protects against postischemic renal injury," American Journal of Physiology-Renal Physiology, vol. 290, no. 6, pp. F1408-F1415, 2006.

[19] S. N. Heyman, S. Rosen, M. Khamaisi, J.-M. Idée, and C. Rosenberger, "Reactive oxygen species and the pathogenesis of radiocontrast-induced nephropathy," Investigative Radiology, vol. 45 , no. 4 , pp. $188-195,2010$.

[20] P. Dawson, A. Becker, and J. M. Holton, "The effect of contrast media on the growth of bacteria," The British Journal of Radiology, vol. 56, no. 671, pp. 809-815, 1983.

[21] M. M. Sendeski, "Pathophysiology of renal tissue damage by iodinated contrast media," Clinical and Experimental Pharmacology and Physiology, vol. 38, no. 5, pp. 292-299, 2011.

[22] A. Pisani, E. Riccio, M. Andreucci et al., "Role of reactive oxygen species in pathogenesis of radiocontrast-induced nephropathy," BioMed Research International, vol. 2013, Article ID 868321, 6 pages, 2013.

[23] P. Pacher, J. S. Beckman, and L. Liaudet, "Nitric oxide and peroxynitrite in health and disease," Physiological Reviews, vol. 87, no. 1, pp. 315-424, 2007.

[24] A. Pisani, M. Sabbatini, E. Riccio et al., "Effect of a recombinant manganese superoxide dismutase on prevention of contrast-induced acute kidney injury," Clinical and Experimental Nephrology, vol. 18, pp. 424431-8, 2014.

[25] C. Quintavalle, M. Brenca, F. de Micco et al., "In vivo and in vitro assessment of pathways involved in contrast media-induced renal cells apoptosis," Cell Death \& Disease, vol. 2, no. 5, article e155, 2011.

[26] H.-C. Lee, J.-G. Chang, H.-W. Yen, I.-H. Liu, W.-T. Lai, and S.-H. Sheu, "Ionic contrast media induced more apoptosis in diabetic kidney than nonionic contrast media," Journal of Nephrology, vol. 24, no. 3, pp. 376-380, 2011.

[27] R. W. Katzberg, "Urography into the 21st century: new contrast media, renal handling, imaging characteristics, and nephrotoxicity," Radiology, vol. 204, no. 2, pp. 297-312, 1997.

[28] P. Aspelin, P. Aubry, S.-G. Fransson, R. Strasser, R. Willenbrock, and K. J. Berg, "Nephrotoxic effects in high-risk patients undergoing angiography," The New England Journal of Medicine, vol. 348, no. 6, pp. 491-499, 2003.

[29] C. P. Taliercio, R. E. Vlietstra, D. M. Ilstrup et al., "A randomized comparison of the nephrotoxicity of iopamidol and diatrizoate in high risk patients undergoing cardiac angiography," Journal of the American College of Cardiology, vol. 17, no. 2, pp. 384-390, 1991.

[30] B. J. Barrett and E. J. Carlisle, "Metaanalysis of the relative nephrotoxicity of high- and low-osmolality iodinated contrast media," Radiology, vol. 188, no. 1, pp. 171-178, 1993.

[31] B. J. Barrett, "Contrast nephrotoxicity," Journal of the American Society of Nephrology, vol. 5, no. 2, pp. 125-137, 1994.

[32] M. Dong, Z. Jiao, T. Liu, F. Guo, and G. Li, "Effect of administration route on the renal safety of contrast agents: a meta-analysis of randomized controlled trials," Journal of Nephrology, vol. 25, no. 3, pp. 290-301, 2012.
[33] M. C. Heinrich, L. Häberle, V. Müller, W. Bautz, and M. Uder, "Nephrotoxicity of iso-osmolar iodixanol compared with nonionic low-osmolar contrast media: meta-analysis of randomized controlled trials," Radiology, vol. 250, no. 1, pp. 68-86, 2009.

[34] K. J. Hardiek, R. E. Katholi, R. S. Robbs, and C. E. Katholi, "Renal effects of contrast media in diabetic patients undergoing diagnostic or interventional coronary angiography," Journal of Diabetes and Its Complications, vol. 22, no. 3, pp. 171-177, 2008.

[35] R. Mehran and E. Nikolsky, "Contrast-induced nephropathy: definition, epidemiology, and patients at risk," Kidney International. Supplement, no. 100, pp. S11-S15, 2006.

[36] M. R. Rudnick, S. Goldfarb, and J. Tumlin, "Contrast-induced nephropathy: is the picture any clearer?" Clinical Journal of the American Society of Nephrology, vol. 3, no. 1, pp. 261-262, 2008.

[37] J. A. Neyra, S. Shah, R. Mooney, G. Jacobsen, J. Yee, and J. E. Novak, "Contrast-induced acute kidney injury following coronary angiography: a cohort study of hospitalized patients with or without chronic kidney disease," Nephrology Dialysis Transplantation, vol. 28, no. 6, pp. 1463-1471, 2013.

[38] A. C. Schoolwerth, D. A. Sica, B. J. Ballermann, and C. S. Wilcox, "Renal considerations in angiotensin converting enzyme inhibitor therapy: a statement for healthcare professionals from the council on the kidney in cardiovascular disease and the council for high blood pressure research of the american heart association," Circulation, vol. 104, no. 16, pp. 1985-1991, 2001.

[39] M. Cirit, O. Toprak, M. Yesil et al., "Angiotensin-converting enzyme inhibitors as a risk factor for contrast-induced nephropathy," Nephron Clinical Practice, vol. 104, no. 1, pp. c20c27, 2006.

[40] D. Kiski, W. Stepper, E. Brand, G. Breithardt, and H. Reinecke, "Impact of renin-angiotensin-aldosterone blockade by angiotensin-converting enzyme inhibitors or AT-1 blockers on frequency of contrast medium-induced nephropathy: a posthoc analysis from the Dialysis-versus-Diuresis (DVD) trial," Nephrology Dialysis Transplantation, vol. 25, no. 3, pp. 759-764, 2010.

[41] M. Y. Rim, H. Ro, W. C. Kang et al., "The effect of reninangiotensin-aldosterone system blockade on contrast-induced acute kidney injury: a propensity-matched study," American Journal of Kidney Diseases, vol. 60, no. 4, pp. 576-582, 2012.

[42] Z. Umruddin, K. Moe, and K. Superdock, "ACE inhibitor or angiotensin II receptor blocker use is a risk factor for contrastinduced nephropathy," Journal of Nephrology, vol. 25, no. 5, pp. 776-781, 2012.

[43] M. A. C. Onuigbo and N. T. C. Onuigbo, "Does reninangiotensin aldosterone system blockade exacerbate contrastinduced nephropathy in patients with chronic kidney disease? A prospective 50-month mayo clinic study," Renal Failure, vol. 30, no. 1, pp. 67-72, 2008.

[44] P. A. McCullough, R. Wolyn, L. L. Rocher, R. N. Levin, and W. W. O’Neill, “Acute renal failure after coronary intervention: incidence, risk factors, and relationship to mortality," American Journal of Medicine, vol. 103, no. 5, pp. 368-375, 1997.

[45] C. P. Taliercio, R. E. Vlietstra, L. D. Fisher, and J. C. Burnett, "Risks for renal dysfunction with cardiac angiography," Annals of Internal Medicine, vol. 104, no. 4, pp. 501-504, 1986.

[46] P. McCullough, "Outcomes of contrast-induced nephropathy: Experience in patients undergoing cardiovascular intervention," Catheterization and Cardiovascular Interventions, vol. 67, no. 3, pp. 335-343, 2006. 
[47] S. T. Cochran, W. S. Wong, and D. J. Roe, "Predicting angiography-induced acute renal function impairment: clinical risk model," American Journal of Roentgenology, vol. 141, no. 5, pp. 1027-1033, 1983.

[48] T. G. Gleeson and S. Bulugahapitiya, "Contrast-induced nephropathy," American Journal of Roentgenology, vol. 183, no. 6, pp. 1673-1689, 2004.

[49] D. B. Oliveira, "Prophylaxis against contrast-induced nephropathy," The Lancet, vol. 353, no. 9165, pp. 1638-1639, 1999.

[50] M. J. Kuhn, N. Chen, D. V. Sahani et al., "The PREDICT study: a randomized double-blind comparison of contrast-induced nephropathy after low- or isoosmolar contrast agent exposure," The American Journal of Roentgenology, vol. 191, no. 1, pp. 151$157,2008$.

[51] L. Byrd and R. L. Sherman, "Radiocontrast-induced acute renal failure: a clinical and pathophysiologic review," Medicine, vol. 58, no. 3, pp. 270-279, 1979.

[52] S. Harkonen and C. Kjellstrand, "Contrast nephropathy," American Journal of Nephrology, vol. 1, no. 2, pp. 69-77, 1981.

[53] G. A. Khoury, J. C. Hopper, Z. Varghese et al., "Nephrotoxicity of ionic and non-ionic contrast material in digital vascular imaging and selective renal arteriography," The British Journal of Radiology, vol. 56, no. 669, pp. 631-635, 1983.

[54] R. D. Moore, E. P. Steinberg, N. R. Powe et al., "Nephrotoxicity of high-osmolality versus low-osmolality contrast media: randomized clinical trial," Radiology, vol. 182, no. 3, pp. 649-655, 1992.

[55] R. W. Katzberg and B. J. Barrett, "Risk of iodinated contrast material-induced nephropathy with intravenous administration," Radiology, vol. 243, no. 3, pp. 622-628, 2007.

[56] D. R. Campbell, B. K. Flemming, W. F. Mason, S. A. Jackson, D. J. Hirsch, and K. J. MacDonald, "A comparative study of the nephrotoxicity of iohexol, iopamidol and ioxaglate in peripheral angiography," Canadian Association of Radiologists Journal, vol. 41, no. 3, pp. 133-137, 1990.

[57] A. S. Gomes, J. D. Baker, V. Martin-Paredero et al., "Acute renal dysfunction after major arteriography," American Journal of Roentgenology, vol. 145, no. 6, pp. 1249-1253, 1985.

[58] E. Seeliger, B. Flemming, T. Wronski et al., "Viscosity of contrast media perturbs renal hemodynamics," Journal of the American Society of Nephrology, vol. 18, no. 11, pp. 2912-2920, 2007.

[59] E. Seeliger, K. Becker, M. Ladwig, T. Wronski, P. B. Persson, and B. Flemming, "Up to 50 -fold increase in urine viscosity with isoosmolar contrast media in the rat," Radiology, vol. 256, no. 2, pp. 406-414, 2010.

[60] E. Seeliger, D. C. Lenhard, and P. B. Persson, "Contrast media viscosity versus osmolality in kidney injury: lessons from animal studies," BioMed Research International, vol. 2014, Article ID 358136, 15 pages, 2014.

[61] G. Jost, H. Pietsch, J. Sommer et al., "Retention of iodine and expression of biomarkers for renal damage in the kidney after application of iodinated contrast media in rats," Investigative Radiology, vol. 44, no. 2, pp. 114-123, 2009.

[62] K. Dyvik, K. Dyrstad, and A. Tronstad, "Relationship between viscosity and determined injection pressure in angiography catheters for common roentgen contrast media," Acta Radiologica. Supplementum, vol. 399, pp. 43-49, 1995.

[63] J. Ueda, A. Nygren, P. Hansell, and U. Erikson, "Influence of contrast media on single nephron glomerular filtration rate in rat kidney: a comparison between diatrizoate, iohexol, ioxaglate, and iotrolan," Acta Radiologica, vol. 33, no. 6, pp. 596599, 1992.
[64] J. Ueda, A. Nygren, P. Hansell, and H. R. Ulfendahl, "Effect of intravenous contrast media on proximal and distal tubular hydrostatic pressure in the rat kidney," Acta Radiologica, vol. 34, no. 1, pp. 83-87, 1993.

[65] M. C. Heinrich, M. K. Kuhlmann, A. Grgic, M. Heckmann, B. Kramann, and M. Uder, "Cytotoxic effects of ionic highosmolar, nonionic monomeric, and nonionic iso-osmolar dimeric iodinated contrast media on renal tubular cells in vitro," Radiology, vol. 235, no. 3, pp. 843-849, 2005.

[66] A. Michael, T. Faga, A. Pisani et al., "Molecular mechanisms of renal cellular nephrotoxicity due to radiocontrast media," BioMed Research International, vol. 2014, Article ID 249810, 10 pages, 2014.

[67] M. Andreucci, "Contrast media and nephrotoxicity: a molecular conundrum," Giornale Italiano di Nefrologia, vol. 28, no. 4, p. 355, 2011.

[68] M. Andreucci, G. Fuiano, P. Presta et al., "Radiocontrast media cause dephosphorylation of Akt and downstream signaling targets in human renal proximal tubular cells," Biochemical Pharmacology, vol. 72, no. 10, pp. 1334-1342, 2006.

[69] M. Andreucci, G. Lucisano, T. Faga et al., "Differential activation of signaling pathways involved in cell death, survival and inflammation by radiocontrast media in human renal proximal tubular cells," Toxicological Sciences, vol. 119, no. 2, pp. 408-416, 2011.

[70] M. Andreucci, T. Faga, D. Russo et al., "Differential activation of signaling pathways by low-osmolar and iso-osmolar radiocontrast agents in human renal tubular cells," Journal of Cellular Biochemistry, vol. 115, no. 2, pp. 281-289, 2014.

[71] M. Andreucci, A. Michael, C. Kramers et al., "Renal ischemia/reperfusion and ATP depletion/repletion in LLC-PK cells result in phosphorylation of FKHR and FKHRL1," Kidney International, vol. 64, no. 4, pp. 1189-1198, 2003.

[72] M. Andreucci, G. Fuiano, P. Presta et al., "Downregulation of cell survival signalling pathways and increased cell damage in hydrogen peroxide-treated human renal proximal tubular cells by alpha-erythropoietin," Cell Proliferation, vol. 42, no. 4, pp. 554-561, 2009.

[73] M. Andreucci, T. Faga, G. Lucisano et al., "Mycophenolic acid inhibits the phosphorylation of NF- $\kappa \mathrm{B}$ and JNKs and causes a decrease in IL-8 release in $\mathrm{H}_{2} \mathrm{O}_{2}$-treated human renal proximal tubular cells," Chemico-Biological Interactions, vol. 185, no. 3, pp. 253-262, 2010.

[74] V. E. Andreucci, D. Russo, B. Cianciaruso, and M. Andreucci, "Some sodium, potassium and water changes in the elderly and their treatment," Nephrology Dialysis Transplantation, vol. 11, supplement 9, pp. 9-17, 1996.

[75] M. Andreucci, S. Federico, and V. E. Andreucci, "Edema and acute renal failure," Seminars in Nephrology, vol. 21, no. 3, pp. 251-256, 2001.

[76] P. A. McCullough, M. E. Bertrand, J. A. Brinker, and F. Stacul, "A meta-analysis of the renal safety of isosmolar iodixanol compared with low-osmolar contrast media," Journal of the American College of Cardiology, vol. 48, no. 4, pp. 692-699, 2006.

[77] R. J. Solomon, M. K. Natarajan, S. Doucet et al., "Cardiac angiography in renally impaired patients (CARE) study: a randomized double-blind trial of contrast-induced nephropathy in patients with chronic kidney disease," Circulation, vol. 115, no. 25, pp. 3189-3196, 2007. 
[78] M. Reed, P. Meier, U. U. Tamhane, K. B. Welch, M. Moscucci, and H. S. Gurm, "The relative renal safety of iodixanol compared with low-osmolar contrast media: a meta-analysis of randomized controlled trials," JACC: Cardiovascular Interventions, vol. 2, no. 7, pp. 645-654, 2009.

[79] L. Bolognese, G. Falsini, C. Schwenke et al., "Impact of iso-osmolar versus low-osmolar contrast agents on contrastinduced nephropathy and tissue reperfusion in unselected patients with ST-segment elevation myocardial infarction undergoing primary percutaneous coronary intervention (from the Contrast Media and Nephrotoxicity Following primary Angioplasty for Acute Myocardial Infarction [CONTRASTAMI] trial)," The American Journal of Cardiology, vol. 109, no. 1, pp. 67-74, 2012.

[80] B. J. Barrett, R. W. Katzberg, H. S. Thomsen et al., "Contrastinduced nephropathy in patients with chronic kidney disease undergoing computed tomography: a double-blind comparison of iodixanol and iopamidol," Investigative Radiology, vol. 41, no. 11, pp. 815-821, 2006.

[81] M. Andreucci, T. Faga, G. B. De Sarro, and A. Michael, "The toxicity of radiographic contrast agents in the clinical practice," Journal of Nephrology Advances. In press.

[82] M. Andreucci, T. Faga, F. Perticone, and A. Michael, "Radiographic contrast agents, drugs useful for diagnostics, but with contrast-induced nephropathy as side effect," Journal of Nephrology and Urology. In press.

[83] R. G. Cigarroa, R. A. Lange, R. H. Williams, and D. Hillis, "Dosing of contrast material to prevent contrast nephropathy in patients with renal disease," The American Journal of Medicine, vol. 86, no. 6, pp. 649-652, 1989.

[84] W. K. Laskey, C. Jenkins, F. Selzer et al., "Volume-to-creatinine clearance ratio: a pharmacokinetically based risk factor for prediction of early creatinine increase after percutaneous coronary intervention," Journal of the American College of Cardiology, vol. 50, no. 7, pp. 584-590, 2007.

[85] H. S. Gurm, S. R. Dixon, D. E. Smith et al., "Renal functionbased contrast dosing to define safe limits of radiographic contrast media in patients undergoing percutaneous coronary interventions," Journal of the American College of Cardiology, vol. 58, no. 9, pp. 907-914, 2011.

[86] J. J. Keaney, C. M. Hannon, and P. T. Murray, "Contrast-induced acute kidney injury: how much contrast is safe?" Nephrology Dialysis Transplantation, vol. 28, no. 6, pp. 1376-1383, 2013.

[87] M. Andreucci, T. Faga, A. Pisani, M. Sabbatini, D. Russo, and A. Michael, "Prevention of contrast-induced nephropathy through a knowledge of its pathogenesis and risk factors," The Scientific World Journal. In press.

[88] H. S. Thomsen, "Guidelines for contrast media from the European society of urogenital radiology," American Journal of Roentgenology, vol. 181, no. 6, pp. 1463-1471, 2003.

[89] H. S. Trivedi, H. Moore, S. Nasr et al., "A randomized prospective trial to assess the role of saline hydration on the development of contrast nephrotoxicity," Nephron Clinical Practice, vol. 93, no. 1, pp. C29-C34, 2003.

[90] C. Mueller, "Prevention of contrast-induced nephropathy with volume supplementation," Kidney International Supplement, no. 100, pp. S16-S19, 2006.

[91] G. J. Merten, W. P. Burgess, L. V. Gray et al., "Prevention of contrast-induced nephropathy with sodium bicarbonate: a randomized controlled trial," The Journal of the American Medical Association, vol. 291, no. 19, pp. 2328-2334, 2004.
[92] M. Masuda, T. Yamada, T. Mine et al., "Comparison of usefulness of sodium bicarbonate versus sodium chloride to prevent contrast-induced nephropathy in patients undergoing an emergent coronary procedure," The American Journal of Cardiology, vol. 100, no. 5, pp. 781-786, 2007.

[93] E. E. Ozcan, S. Guneri, B. Akdeniz et al., "Sodium bicarbonate, $\mathrm{N}$-acetylcysteine, and saline for prevention of radiocontrastinduced nephropathy. A comparison of 3 regimens for protecting contrast-induced nephropathy in patients undergoing coronary procedures. A single-center prospective controlled trial," American Heart Journal, vol. 154, no. 3, pp. 539-544, 2007.

[94] A. Tamura, Y. Goto, K. Miyamoto et al., "Efficacy of single-bolus administration of sodium bicarbonate to prevent contrastinduced nephropathy in patients with mild renal insufficiency undergoing an elective coronary procedure," The American Journal of Cardiology, vol. 104, no. 7, pp. 921-925, 2009.

[95] S. D. Navaneethan, S. Singh, S. Appasamy, R. E. Wing, and A. R. Sehgal, "Sodium bicarbonate therapy for prevention of contrastinduced nephropathy: a systematic review and meta-analysis," American Journal of Kidney Diseases, vol. 53, no. 4, pp. 617-627, 2009.

[96] E. A. J. Hoste, J. J. de Waele, S. A. Gevaert, S. Uchino, and J. A. Kellum, "Sodium bicarbonate for prevention of contrastinduced acute kidney injury: a systematic review and metaanalysis," Nephrology Dialysis Transplantation, vol. 25, no. 3, pp. 747-758, 2010.

[97] M. Joannidis, M. Schmid, and C. J. Wiedermann, "Prevention of contrast media-induced nephropathy by isotonic sodium bicarbonate: a meta-analysis," Wiener Klinische Wochenschrift, vol. 120, no. 23-24, pp. 742-748, 2008.

[98] F. Assadi, "Acetazolamide for prevention of contrast-induced nephropathy: a new use for an old drug," Pediatric Cardiology, vol. 27, no. 2, pp. 238-242, 2006.

[99] M. Pakfetrat, M. H. Nikoo, L. Malekmakan et al., "A comparison of sodium bicarbonate infusion versus normal saline infusion and its combination with oral acetazolamide for prevention of contrast-induced nephropathy: a randomized, double-blind trial," International Urology and Nephrology, vol. 41, no. 3, pp. 629-634, 2009.

[100] J.-S. Jang, H.-Y. Jin, J.-S. Seo et al., "Sodium bicarbonate therapy for the prevention of contrast-induced acute kidney injury-a systematic review and meta-analysis," Circulation Journal, vol. 76, no. 9, pp. 2255-2265, 2012.

[101] C. Briguori, F. Airoldi, D. D’Andrea et al., "Renal insufficiency following contrast media administration trial (REMEDIAL): a randomized comparison of 3 preventive strategies," Circulation, vol. 115, no. 10, pp. 1211-1217, 2007.

[102] D. Reddan, M. Laville, and V. D. Garovic, "Contrast-induced nephropathy and its prevention: what do we really know from evidence-based findings?" Journal of Nephrology, vol. 22, no. 3, pp. 333-351, 2009.

[103] C. S. R. Baker, A. Wragg, S. Kumar, R. De Palma, L. R. I. Baker, and C. J. Knight, "A rapid protocol for the prevention of contrast-induced renal dysfunction: the RAPPID study," Journal of the American College of Cardiology, vol. 41, no. 12, pp. 2114-2118, 2003.

[104] M. Andreucci, "Statins inCIN: a problemat least partly solved?" Giornale Italiano di Nefrologia, vol. 30, no. 3, 2013.

[105] M. Sabbatini, A. Pisani, F. Uccello et al., "Atorvastatin improves the course of ischemic acute renal failure in aging rats," Journal of the American Society of Nephrology, vol. 15, no. 4, pp. 901-909, 2004 . 
[106] S. Khanal, N. Attallah, D. E. Smith et al., "Statin therapy reduces contrast-induced nephropathy: an analysis of contemporary percutaneous interventions," The American Journal of Medicine, vol. 118, no. 8, pp. 843-849, 2005.

[107] G. Patti, A. Nusca, M. Chello et al., "Usefulness of statin pretreatment to prevent contrast-induced nephropathy and to improve long-term outcome in patients undergoing percutaneous coronary intervention," The American Journal of Cardiology, vol. 101, no. 3, pp. 279-285, 2008.

[108] B.-C. Zhang, W.-M. Li, and Y.-W. Xu, "High-dose statin pretreatment for the prevention of contrast-induced nephropathy: a meta-analysis," Canadian Journal of Cardiology, vol. 27, no. 6, pp. 851-858, 2011.

[109] M. Leoncini, A. Toso, M. Maioli, F. Tropeano, and F. Bellandi, "Statin treatment before percutaneous cononary intervention," Journal of Thoracic Disease, vol. 5, no. 3, pp. 335-342, 2013.

[110] G. Patti, E. Ricottini, A. Nusca et al., "Short-term, highdose atorvastatin pretreatment to prevent contrast-induced nephropathy in patients with acute coronary syndromes undergoing percutaneous coronary intervention (from the ARMYDA-CIN [atorvastatin for reduction of myocardial damage during angioplasty-contrast-induced nephropathy] trial," The American Journal of Cardiology, vol. 108, no. 1, pp. 1-7, 2011.

[111] C. Quintavalle, D. Fiore, F. de Micco et al., "Impact of a high loading dose of atorvastatin on contrast-induced acute kidney injury," Circulation, vol. 126, no. 25, pp. 3008-3016, 2012.

[112] R. Solomon, C. Werner, D. Mann, J. D’Elia, and P. Silva, “Effects of saline, mannitol, and furosemide on acute decreases in renal function induced by radiocontrast agents," The New England Journal of Medicine, vol. 331, no. 21, pp. 1416-1420, 1994.

[113] J.-M. Weinstein, S. Heyman, and M. Brezis, "Potential deleterious effect of furosemide in radiocontrast nephropathy," Nephron, vol. 62, no. 4, pp. 413-415, 1992.

[114] L. S. Weisberg, P. B. Kurnik, and B. R. Kurnik, "Risk of radiocontrast nephropathy in patients with and without diabetes mellitus," Kidney International, vol. 45, no. 1, pp. 259-265, 1994.

[115] C. Briguori, G. Visconti, B. Ricciardelli, and G. Condorelli, "Renal insufficiency following contrast media administration trial II (REMEDIAL II): renalGuard system in high-risk patients for contrast-induced acute kidney injury: rationale and design," EuroIntervention, vol. 6, no. 9, pp. 1117-1122, 2011.

[116] B. Vogt, P. Ferrari, C. Schönholzer et al., "Prophylactic hemodialysis after radiocontrast media in patients with renal insufficiency is potentially harmful," The American Journal of Medicine, vol. 111, no. 9, pp. 692-698, 2001.

[117] M. Andreucci, "Radiographic contrast nephropathy," Giornale Italiano di Nefrologia, vol. 31, no. 5, 2014.

[118] J. J. Pasternak and E. E. Williamson, "Clinical pharmacology, uses, and adverse reactions of iodinated contrast agents: a primer for the non-radiologist," Mayo Clinic Proceedings, vol. 87, no. 4, pp. 390-402, 2012. 


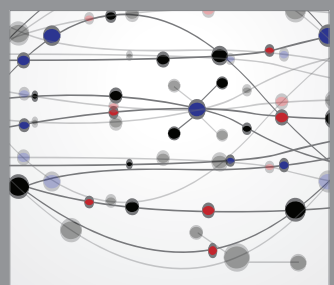

The Scientific World Journal
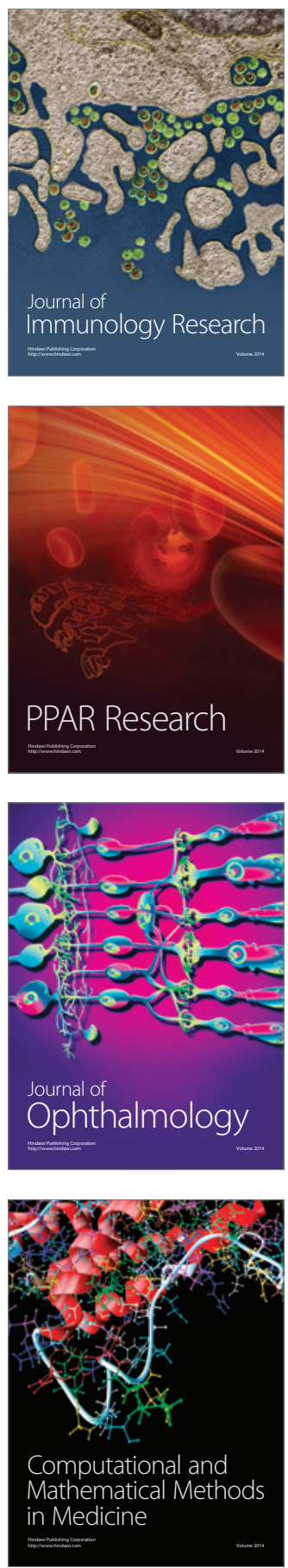

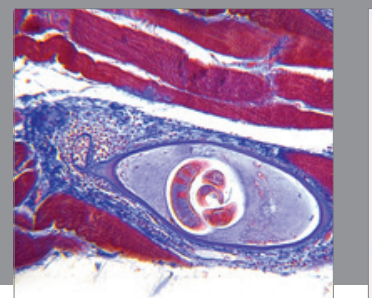

Gastroenterology

Research and Practice
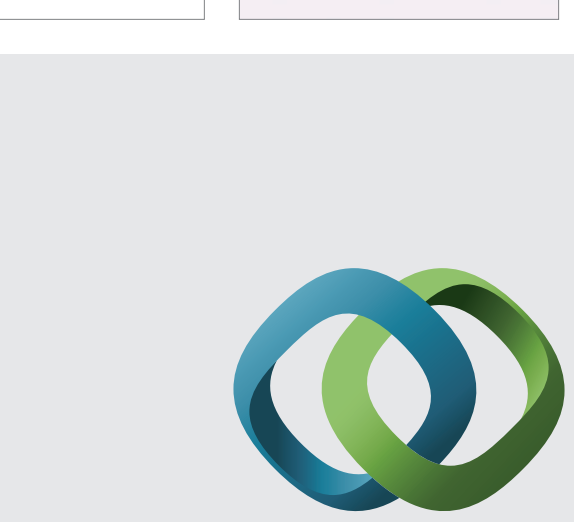

\section{Hindawi}

Submit your manuscripts at

http://www.hindawi.com
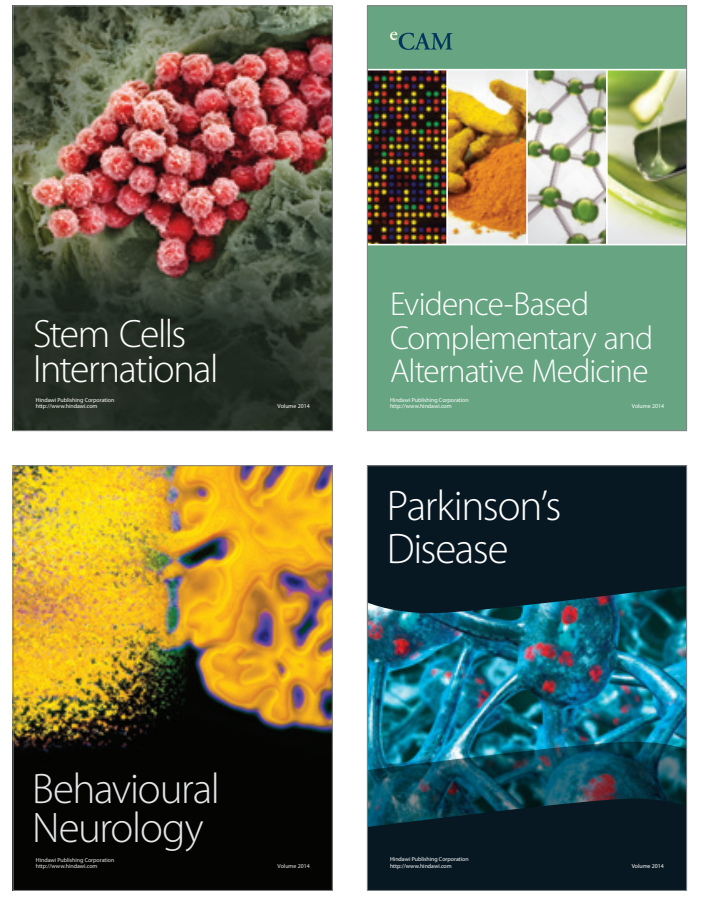
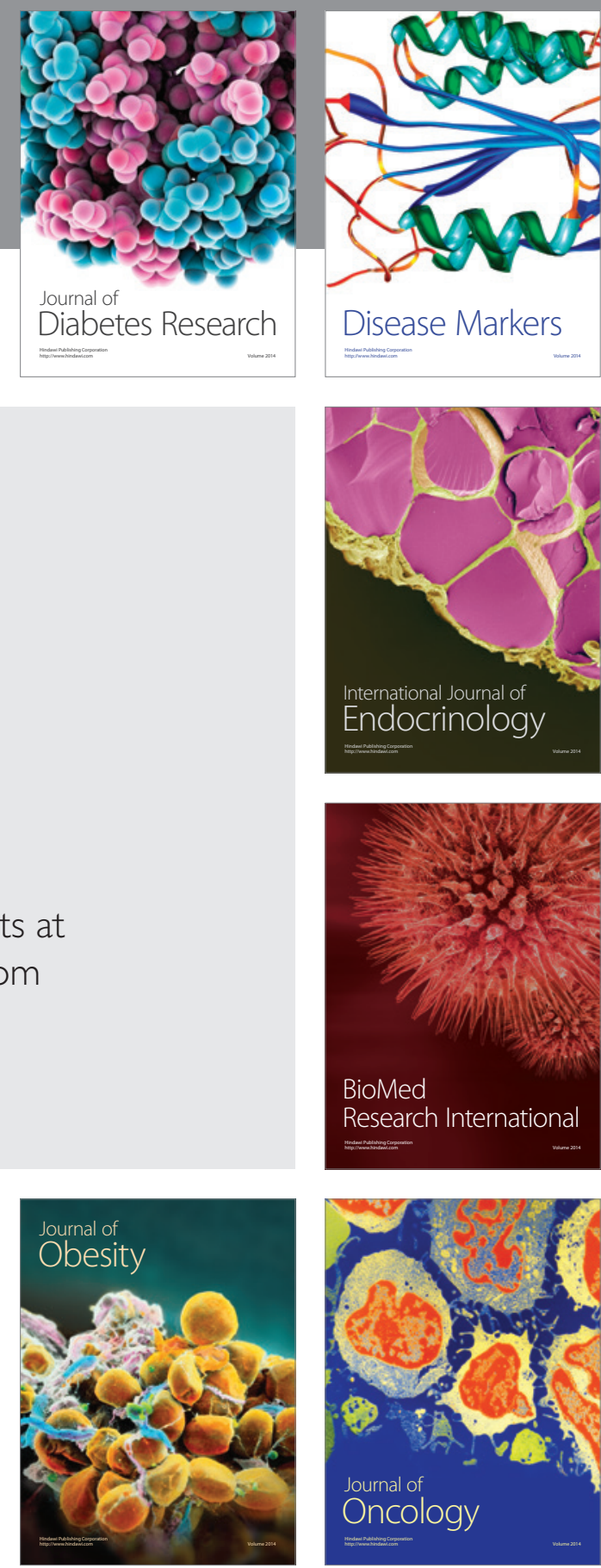

Disease Markers
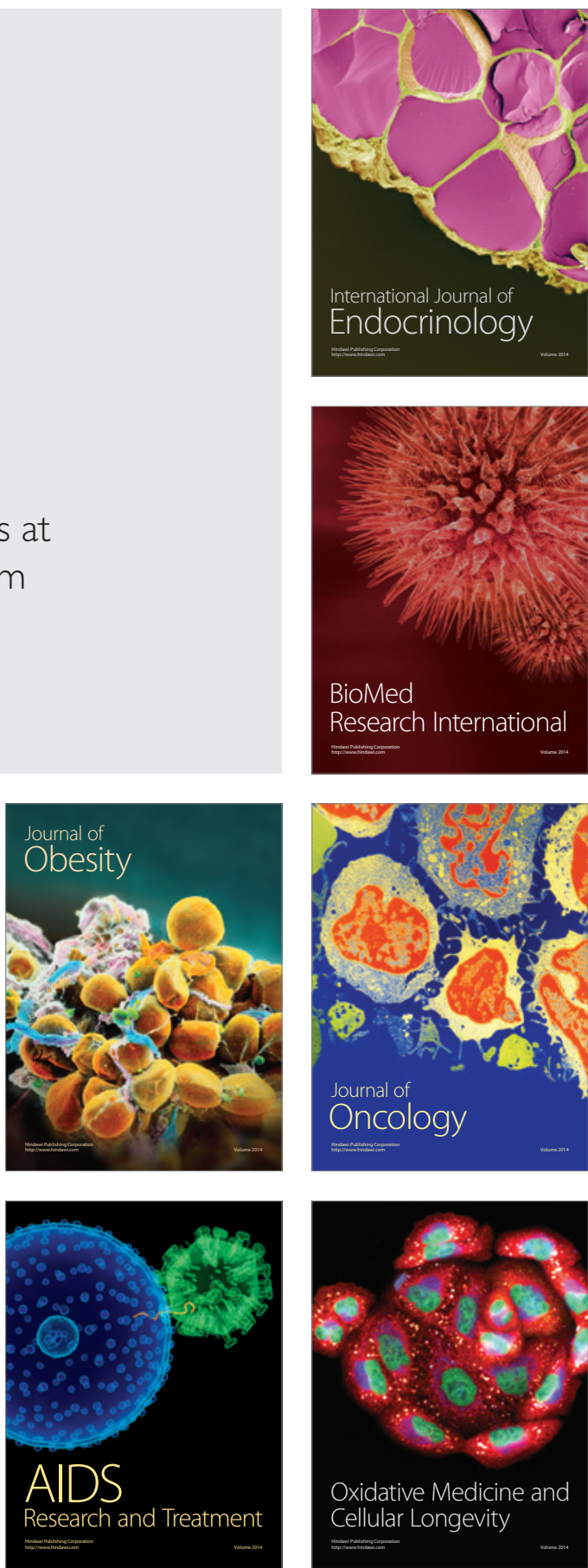